\title{
Numerical Study on Aerodynamic Drag Reduction of an Urban-Concept Car for Energy-Efficient Competition
}

\author{
Himsar Ambarita ${ }^{1}$ and Munawir R Siregar ${ }^{2}$ \\ ${ }^{1}$ Sustainable Energy Research Centre, Faculty of Engineering, Universitas Sumatera Utara, Kampus USU, Medan 20155, Indonesia \\ ${ }^{2}$ Sarulla Operation Ltd., The Energy Building $51^{\text {st }}$ floor, SCBD Lot 11 A, Jl. Jend. Sudirman Jakarta 12190, Indonesia
}

\begin{abstract}
The present work deals with aerodynamic drag reduction of an urban-concept car for energy-efficient competition. Several modifications have been proposed to the original design of the urban-concept of the car. In order to investigate the effect of the proposed modifications numerical method has been developed. In the numerical method three-dimensional governing equations have been solved numerically. Turbulent flow is modeled using $k$ epsilon model. The two designs have been simulated at five different inlet velocities. The inlet velocity varies from 10 $\mathrm{m} / \mathrm{s}$ to $20 \mathrm{~m} / \mathrm{s}$. The velocity contour, velocity vector and pressure distributions have been plotted. The results show that the proposed modifications improve the performance of the proposed design. At the given inlet velocities, the aerodynamic drag coefficient of the new design decreased $26.63 \%$ in comparison with original design. It is recommended to modify the original design of the urban concept car by implementing the proposed modifications. The new design will improve the performance of the urban concept car.
\end{abstract}

\section{Introduction}

Shell Eco-marathon is a competition that challenges students around the world to design, build and drive the most energy-efficient car. There are three annual events in Asia, Americas, and Europe. In each event, the student team takes to the track to examine who goes further with the less amount of fuel [1]. The University of Sumatera Utara (USU) participates in Shell Eco-marathons Asia every year. The student team of USU named as HORAS team. The HORAS team also participates in Indonesian national level of similar competition known as National energy-efficient car contest (named as KMHE). The Horas team consists of students from Mechanical Engineering of USU. The HORAS team has designed an urban concept car. In order to get the better performance the urban concept car has been modified several times. Many modifications have been implemented to the car. One of the important modification is the body of the car. It is designed to meet the high aerodynamic performance in order to reduce fuel consumption. The better aerodynamic performance of the car is one of the solution to produce an energy-efficient which can reduce the drag force of the body. Typically, 3-11\% of energy from fuel is burnt to overcome the aerodynamic load. Thus, the study on aerodynamic drag reduction will give significant contribution to reducing fuel consumption. This is the background of this study.

Several studies on aerodynamic performance in a car habe been reported in literature. Taha et al. used commercial numerical code of Fluent to investigate aerodynamics characteristics of "Merdeka 2" a prototype of a solar vehicle that participated in the world solar challenge [2]. The body of the car was designed based on box fish which was also claimed the concept design of Mercedes Benz minivan. The turbulent governing equations were solved numerically. Reynold-averaged Navier-Stokes with the $k$-epsilon model were used to model the turbulent flow. It was stated that the numerical and experimental results do not agree well. Krishnani [3] employed commercial code to examine the drag reduction of a generic sports utility vehicle. The study has examined the effect of external devices like spoilers, vortex strake device and under-carriage flow device on reducing aerodynamic drag in a vehicle. Franck et al. [4] investigated flow around the Ahmed Vehicle model using numerical simulation with several turbulence models.

Kim et al. [5] reported the examination on salient drag reduction of a heavy vehicle using modified cab-roof fairings. The results are to provide useful information for the design of new cab-roof fairing models and the improvement of the aerodynamic performance of heavy vehicles, including trucks and tractor-trailers. Shim et al. [6] reported the investigation on the optimization of bobsleigh bumper shape to reduce aerodynamic drag in a vehicle. In order to solve the turbulent equations, $k$ omega shear stress transport turbulence model is used to close the three-dimensional Reynolds averaged NavierStokes equation. A parametric study was conducted using six parameters related to the shape of the front and rear bumpers and three parameters, i.e., the distance between the bumpers and the ground and leading angle of the front 
bumper as design parameters. The objective function for optimization was the aerodynamic drag coefficient. The results showed that aerodynamic drag of the bobsleigh was reduced by $3.08 \%$ in comparison with the reference design. Lorite-Diez et al. [7] investigated the use of the adjoint sensitivity formulation to design efficient passive control strategies intending at reducing the drag coefficient of a slender blunt-based body with a straight rear cavity.

Computational Fluid Dynamics (CFD) code plays an important role to explore the fluid flow characteristics in order to design and to promote modification of a racecar. Kieffer et al. [8] employed CFD to study the section characteristics of Formula Mazda race car wings. The commercial STAR-CD CFD code was used to perform the simulation. The turbulent flow was modeled using $k$ epsilon model. The results are presented graphically. It was shown the pressure and velocity distributions and lift and drag coefficients for the different cases. The results were claimed to be valuable for improving the optimum handling of Formula Mazda race cars. Mariani et al. [9] reported a study that aimed to improve the external fluiddynamics of the first prototype of the Formula-SAE (Society of Automotive Engineers) race car of the University of Perugia, Italy prepared for participation in the international competition of Varano (Parma-Italy). Two prototypes were analyzed numerically; the original prototype and redesigning prototype. The results showed that a remarkable improvement of the aerodynamics performance was obtained by the proposed modifications. Hassan et al. [10] reported an investigation on aerodynamic drag reduction of racing cars by using a numerical method. In the method, Favre-averaged Navier-Stokes equations solved using $k$-epsilon turbulence model. Those equations were solved using Finite Volume Method. The results showed that the drag coefficient of the car was 0.3233 and it was evident that the drag can be reduced up to $22.13 \%$ by different rear under-body modifications and it can be up to $9.5 \%$ by exhaust gas redirection towards the separated region at the rear of the car. Hetawal et al. [11] reported the investigation on rear engine Formula SAE racecar. The objective was to investigate the aerodynamic characteristics of a SAE race car with a front spoiler, without the front spoiler, and with firewall vent. The study was conducted by employing Fluent CFD software with k-epsilon turbulence model. The results were graphically presented with drag coefficient and velocity contour.

Recently, Ambarita et al. employed CFD to explore the aerodynamic characteristics of an urban concept car for energy-efficient competition [12]. The aerodynamic characteristics of the urban concept car designed by HORAS team has been investigated numerically. The objective of the study was to explore the aerodynamics characteritics. The results showed that the aerodynamic drag of the car was high and even higher than a commercial city car. It was suggested to further investigate several modifications in order to reduce the aerodynamic drag. In this study, several modifications are proposed. The effects of the modifications on the aerodynamic drag reduction are examined. The results are expected to supply necessary information for designing of an energy-efficient car

\section{Method}

Numerical approach is used to solve the problem. The used governing equations are explained as follows. Three-dimensional governing equations are used to solve the fluid flow problem and the turbulence mode is employed to model the flow. The continuity equation and momentum equation are formulated as follows.

$$
\begin{gathered}
\frac{\partial \rho}{\partial t}+\frac{\partial}{\partial x_{i}}\left(\rho u_{i}\right)=0 \\
\rho \frac{D u_{i}}{D t}=-\frac{\partial p}{\partial x_{i}}+\frac{\partial}{\partial x_{j}}\left[\mu\left(\frac{\partial u_{i}}{\partial x_{j}}+\frac{\partial u_{j}}{\partial x_{i}}-\frac{2}{3} \delta_{i j} \frac{\partial u_{i}}{\partial x_{i}}\right)\right] \\
+\frac{\partial}{\partial x_{j}}\left(-\overline{\rho u_{i}^{\prime} u_{j}^{\prime}}\right)
\end{gathered}
$$

The last term of the right side of equation (2) is known as the Reynolds-stresses tensor. It represents the transfer of momentum due to turbulent fluctuations. This tensor can be calculated using below equation.

$$
-\rho \overline{v_{i}^{\prime} v_{j}^{\prime}}=-\rho\left(\overline{v_{i}^{\prime} v_{j}^{\prime}}-\bar{v}_{i} \bar{v}_{j}\right)
$$

In this method, Boussinesq hypothesis is employed to relate the stresses with the mean velocity gradients. Using this assumption, the Reynolds-stresses can be calculated using the following equation.

$$
-\overline{\rho u_{i}^{\prime} u_{j}^{\prime}}=\mu_{t}\left(\frac{\partial u_{i}}{\partial x_{j}}+\frac{\partial u_{j}}{\partial x_{i}}\right)-\frac{2}{3}\left(\rho k+\mu_{t} \frac{\partial u_{i}}{\partial x_{i}}\right) \delta_{i j}
$$

The standard $k-\varepsilon$ turbulence model is employed to close the equation (4). The additional governing equations, turbulent kinetic energy $(k)$ equation and the turbulent dissipation rate $(\varepsilon)$, are calculated as follows.

$$
\begin{aligned}
\rho \frac{D k}{D t}= & \frac{\partial}{\partial x_{i}}\left[\left(\mu+\frac{\mu_{t}}{\sigma_{k}}\right) \frac{\partial k}{\partial x_{i}}\right]+G_{k}+G_{b}-\rho \varepsilon-Y_{M} \\
\rho \frac{D \varepsilon}{D t}= & \frac{\partial}{\partial x_{i}}\left[\left(\mu+\frac{\mu_{t}}{\sigma_{\varepsilon}}\right) \frac{\partial \varepsilon}{\partial x_{i}}\right]+C_{1 \varepsilon} \frac{\varepsilon}{k}\left(G_{k}+C_{3 \varepsilon} G_{b}\right) \\
& -C_{2 \varepsilon} \rho \frac{\varepsilon^{2}}{k}
\end{aligned}
$$

The turbulent viscosity $\mu_{t}$ is calculated by the below equation.

$$
\mu_{t}=\rho C_{\mu} \frac{k^{2}}{\varepsilon}
$$

The coefficients $G_{k}, G_{k}$ and $Y_{M}$ represent the generation of turbulent kinetic energy due to mean velocity gradient, generation of turbulent kinetic energy due to buoyancy and the contribution of fluctuating dilation in compressible turbulence to the overall 
dissipation rate, respectively. In addition, the parameter $C_{1 \varepsilon}, C_{2 \varepsilon}, C_{3 \varepsilon}$ and $C_{\mu}$ are constants. While, $\sigma_{k}$ and $\sigma_{\varepsilon}$ are the turbulent Prandtl numbers for $k$ and $\varepsilon$, respectively.

The governing equations were discretized upon threedimensional computational domain. The used mesh, computational domain, car position and the boundary conditions are shown in Figure 1. Here, only a half of the computational domain is taken into simulation. The boundary conditions are explained in Table 1.Use A4 paper size $(210 \times 297 \mathrm{~mm})$ and adjust the margins to those shown in Table 1. The final printed area will be 172 x $252 \mathrm{~mm}$.

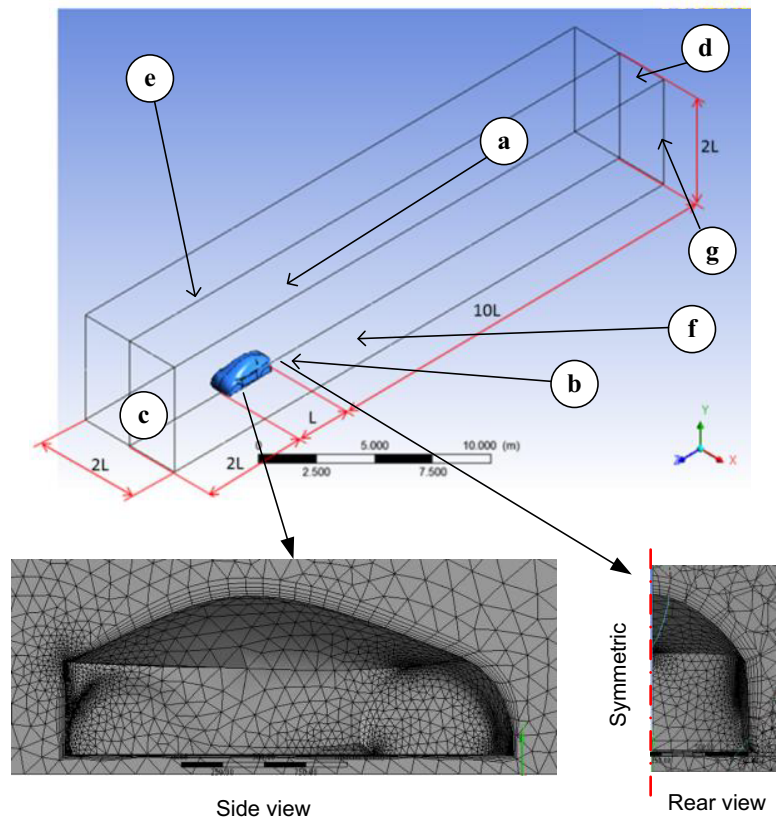

Figure 1. Computational Domain

The governing equations are discretized using second order upwind scheme. The system equations and boundary conditions are solved iteratively using SIMPLE algorithm. The aerodynamic performance will be examined using drag coefficient $\left(C_{D}\right)$. The coefficient is formulated using the below equation.

$$
C_{D}=\frac{F_{D}}{\frac{1}{2} \rho V^{2} A_{D}}
$$

Where $F_{D}[\mathrm{~N}], \rho\left[\mathrm{kg} / \mathrm{m}^{3}\right], V[\mathrm{~m} / \mathrm{s}]$ and $A_{D}\left[\mathrm{~m}^{2}\right]$ are drag force, density, fluid inlet velocity and frontal area of drag force.

Table 1. Boundary Conditions

\begin{tabular}{|c|l|l|}
\hline $\begin{array}{c}\text { Boundary } \\
\text { mark }\end{array}$ & Location & Boundary condition \\
\hline$a$ & Top domain & Pressure outlet $(0 \mathrm{~Pa})$ \\
\hline$b$ & Car surface & Wall \\
\hline$c$ & Inlet & $\begin{array}{l}\text { Velocity inlet (varied from } 10 \text { to } \\
20 \mathrm{~m} / \mathrm{s})\end{array}$ \\
\hline$d$ & Outlet domain & Pressure outlet $(0 \mathrm{~Pa})$ \\
\hline$e$ & Symmetry & Symmetry \\
\hline
\end{tabular}

\begin{tabular}{|c|l|l|}
\hline $\begin{array}{c}\text { Boundary } \\
\text { mark }\end{array}$ & Location & Boundary condition \\
\hline & Plane & \\
\hline$f$ & Bottom/road & Wall \\
\hline$g$ & Right side & Pressure outlet $(0 \mathrm{~Pa})$ \\
\hline
\end{tabular}

As mentioned in the previous section, the objective of this study is to examine the effect of the propose modifications on the aerodynamic drag. The original design and modified designs are shown in Figure 2. The fluid flow and aerodynamic drag of these two designs are investigated numerically using the explained method.
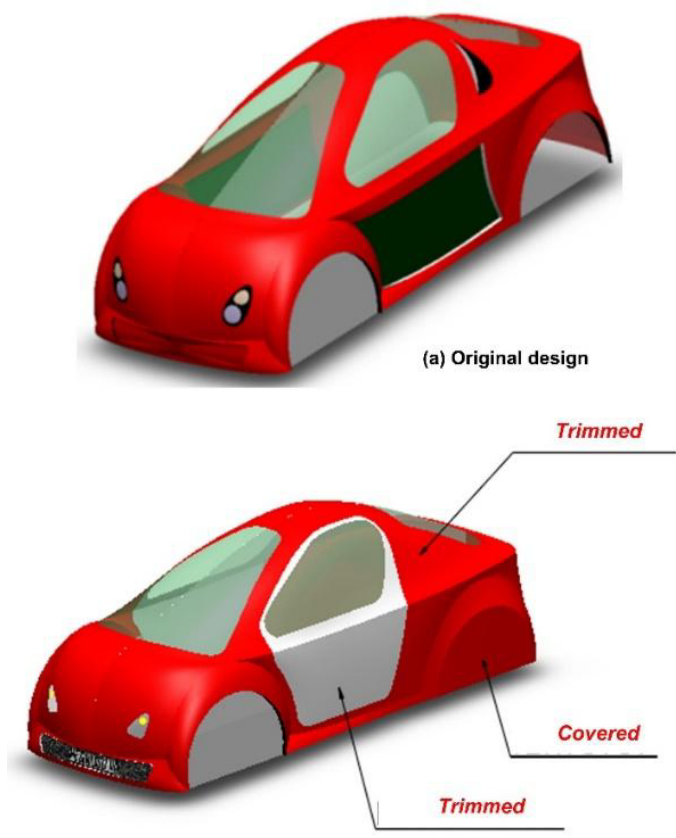

(b) Modified design

Figure 2. Original and Modified Designs

\section{Results and Discussions}

The numerical simulations on the original and modified designs have been carried out at five different inlet velocities. They are $10 \mathrm{~m} / \mathrm{s}, 12.5 \mathrm{~m} / \mathrm{s}, 15 \mathrm{~m} / \mathrm{s}, 17.5 \mathrm{~m} / \mathrm{s}$ and $20 \mathrm{~m} / \mathrm{s}$. In the first section of the result the numerical method will be validated with Ahmed body. The discussion will be followed by fluid flow characteristics and aerodynamic drag.

Table 2. Result Comparisons

\begin{tabular}{|l|c|c|c|}
\hline Parameter & $\begin{array}{c}\text { Experimental } \\
\text { work [4] }\end{array}$ & $\begin{array}{c}\text { Simulation } \\
\text { [4] }\end{array}$ & $\begin{array}{c}\text { Present } \\
\text { Work }\end{array}$ \\
\hline Drag Coef. & 0.2300 & 0.2346 & 0.239034 \\
\hline Diff. [\%] & - & $2.00 \%$ & $3.93 \%$ \\
\hline
\end{tabular}

\subsection{Numerical Validation}

The developed numerical method is firstly validated. The present method has been used to calculate drag coefficient of Ahmed Body. The drag coefficient resulted 
from experimental and numerical works are presented in Table 2. The results show that the the present numerical method does agree well with previous works. The discrepancy to the experimental work is only $3.93 \%$. Thus, the present method will be used to investigate the effect of the modifications.

\subsection{Fluid flow characteristics}

Velocity contour and velocity vector in the rear area of the modified designs are shown in Figure 3(a) and 3(b), respectively. The velocity contour shows that the magnitude of the velocity on the front area is minimum. The maximum velocity is captured above the car. The reversal flow is captured in the rear area of the car. Figure 3(b) clearly shows the reversal flow. The difference of the velocity between front and rear body related to drag force.
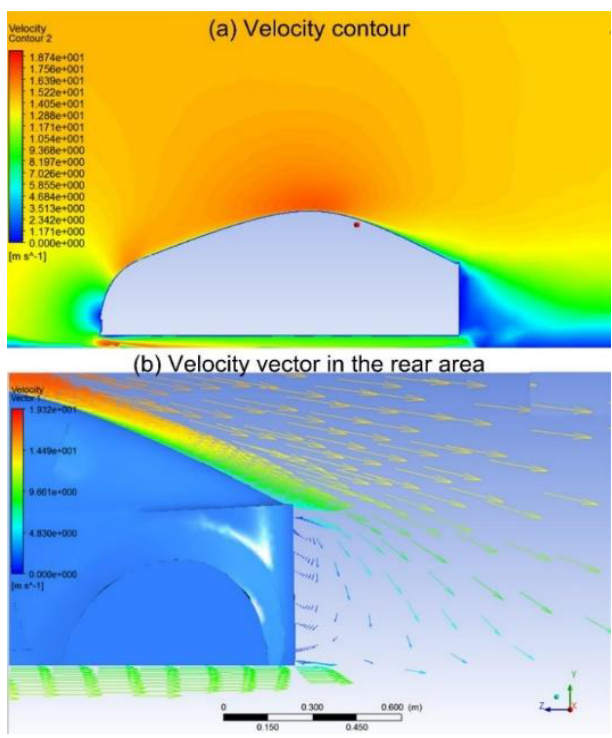

Figure 3. Velocity Contour and Vector

(a) Original design

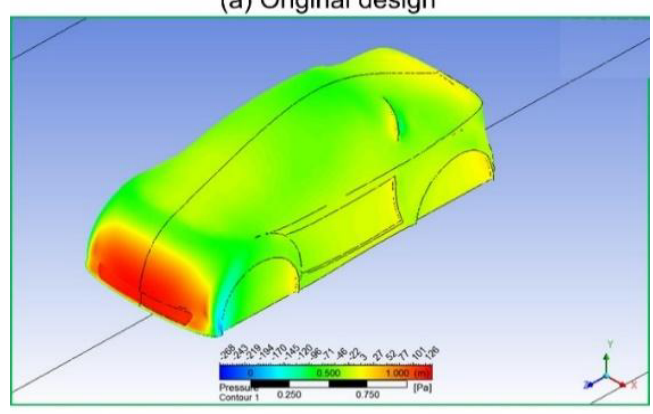

(b) Modified design

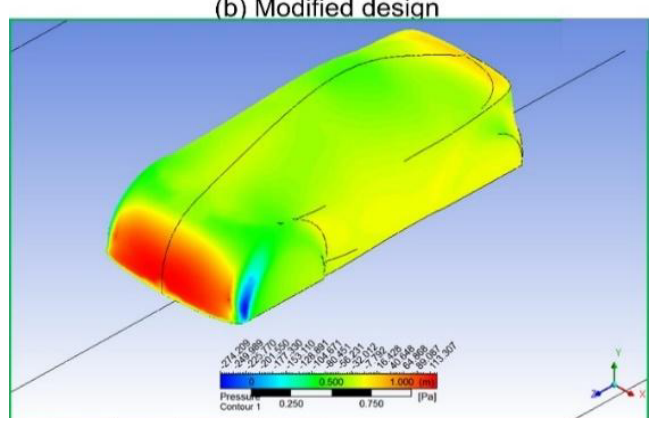

Figure 4. Comparison of Pressure contour
Figure 4 shows the comparison of pressure contour on the surfaces of the two designs. Figure 4(a) shows that minimum and maximum pressure on the original design are $-268 \mathrm{~Pa}$ and $126 \mathrm{~Pa}$, respectively. The pressure difference is $394 \mathrm{~Pa}$. On the other hand, the modified design, shown in Figure 5(b), the minimum and maximum pressures are $-274.2 \mathrm{~Pa}$ and $113.3 \mathrm{~Pa}$. Thus, the pressure difference is $387.5 \mathrm{~Pa}$. The pressure difference of the modified design is lower than the original mode. This fact suggests that the proposed modification results in lower pressure difference on the modified design.

\subsection{Drag coefficient}

The fluid flow characteristics are used to calculated the aerodynamic drag coefficient of the original and modified designs. Equation (8) is used to calculate the drag coefficient. The calculations are made for five different inlet velocities. Figure 5 shows the drag coefficients of the original design and modified designs. It can be seen that the drag coefficient at inlet velocity $10 \mathrm{~m} / \mathrm{s}$ for the original design and modified design are 0.343 and 0.260 , respectively. This value reveals that the reduction of aerodynamic pressure is $24.25 \%$. At inlet velocity of 12.5 $\mathrm{m} / \mathrm{s}$, the drag coefficient of original design and modified design are 0.330 and 0.245 , respectively. Here the drag coefficient reduction is $26.58 \%$. Similar calculations have been made. The drag coefficient reductions at inlet velocity $15 \mathrm{~m} / \mathrm{s}, 17.5 \mathrm{~m} / \mathrm{s}$ and $20 \mathrm{~m} / \mathrm{s}$ are $27.01 \%, 27.52 \%$, and $27.78 \%$, respectively. These values reveal that the proposed modification successfully reduce the drag coefficient of the car body. For velocity ranges from 10 $\mathrm{m} / \mathrm{s}$ to $20 \mathrm{~m} / \mathrm{s}$, the average reduction is $26.63 \%$.

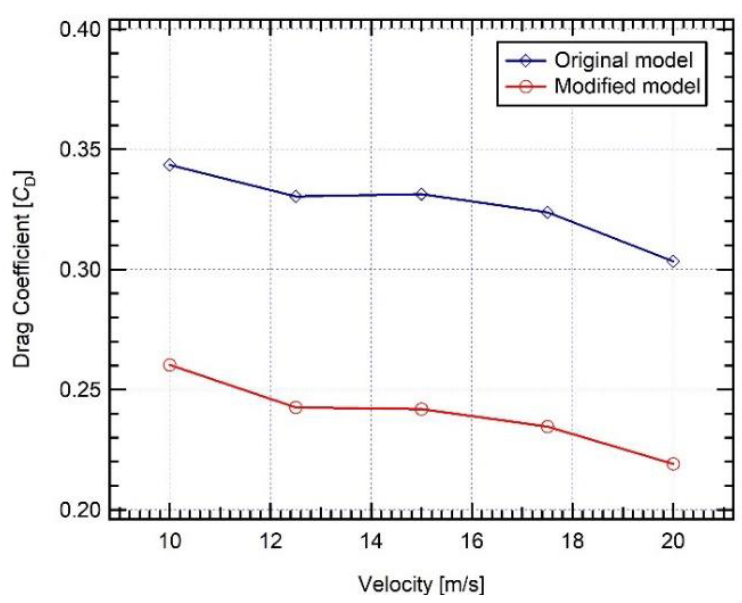

Figure 5. Comparison of Drag coefficient

\section{Conclusions}

To improve the performance of an urban concept car for energy-efficient competition several modifications of the original design have been proposed. Numerical method has been developed to investigate the improvement of the modified design. The aerodynamic drag coefficient is used as performance comparison. The modified design has been simulated at five different inlet velocities, varies 
from $10 \mathrm{~m} / \mathrm{s}$ to $20 \mathrm{~m} / \mathrm{s}$. The fluid flow characteristics have been presented and the aerodynamic drag coefficients have been compared. The conclusions of the present study are as follows. The proposed modifications shown a better performance in comparison with the original design. At the given inlet velocity, the aerodynamic drag coefficient of the proposed design is lower $26.63 \%$ (in averaged) in comparison with the original design. It is recommended to modify the original design of the urban concept car by implementing the proposed modifications. The new design will improve the performance of the urban concept car.

\section{References}

1. http://www.shell.com/energy-and-innovation/shellecomarathon /about.html (Acessed February 4, 2018)

2. Z. Taha, R. Passarella, Sugiyono, N. Abd Rahim, J. Md Sah and A. Ahmad-Yazid, "CFD analysis for merdeka 2 solar vehicle", Advanced Science Letter 4, 2011, 2807-2811.

3. P. N. Krishnani, "CFD Study of drag reduction of a generic sport utility vehicle" Mumbai; Mumbai University, 2009.

4. G. Franck, N. Nigro, M. Storti and J. D'Elia,"Numerical Simulation of the flow around the Ahmed vehicle model", Latin American Applied Research 39, 2009, 295-306.

5. J.J. Kim , S. Lee, M. Kim, D. You and S.J. Lee, "Saline drag reduction of a heavy vehicle using modified cab-roof fairings", Journal of Wind
Engineering \& Industrial Aerodynamics 164, 2017, 138-151.

6. H.S. Shim, Y.N. Lee and K.Y. Kim, "Optimization of bobsleigh bumper shape to reduce aerodynamic drag", Journal of Wind Engineering \& Industrial Aerodynamics 164, 2017, 108-118.

7. M. Lorite-Diez, J.I. Jimenez-Gonzales, C. GutierrezMontes and C. Martinez-Bazan, "Drag reduction of slender blunt-based bodies using optimized rear cavities", Journal of Fluids and Structure 74, 2017, 158-177.

8. W. Kieffer, S. Moujaes and N. Armbya, "CFD study of section characteristics of Formula Mazda race car wings", Mathematical and Computer Modelling 43, 2006, 1275-1287.

9. F. Mariani, C. Poggiani, F. Risi and L. Scappaticci, "Formula-SAE racing car: Experimental and numerical analysis of the external aerodynamics", Energy Procedia 81, 2015, 1013-1029.

10. S.M.R Hassan, T. Islam, M. Ali and M. Q. Islam, "Numerical study on aerodynamic drag reduction of racing cars", Procedia Engineering 90, 2014, 308313.

11. S. Hetawal, M. Gophane, B.K. Ajay and Y. Mukkamala, "Aerodynamic study of formula SAE car", Procedia Engineering 972014 1198-1207.

12. H. Ambarita, M. R. Siregar and H. Kawai, "Study on aerodynamics characteritics an urban concept car for energy efficient competition", IOP Conf. Series: Material Science and Engineering 343 (2018) 01205. 